\title{
Nutritional interventions in critical illness
}

\author{
Jeremy Powell-Tuck \\ Department of Human Nutrition, The Royal London Hospital, Whitechapel, London E1 1BB, UK
}

\begin{abstract}
The metabolism of critical illness is characterized by a combination of starvation and stress. There is increased production of cortisol, catecholamines, glucagon and growth hormone and increased insulin-like growth factor-binding protein-1. Phagocytic, epithelial and endothelial cells elaborate reactive oxygen and nitrogen species, chemokines, pro-inflammatory cytokines and lipid mediators, and antioxidant depletion ensues. There is hyperglycaemia, hyperinsulinaemia, hyperlactataemia, increased gluconeogenesis and decreased glycogen production. Insulin resistance, particularly in relation to the liver, is marked. The purpose of nutritional support is primarily to save life and secondarily to speed recovery by reducing neuropathy and maintaining muscle mass and function. There is debate about the optimal timing of nutritional support for the patient in the intensive care unit. It is generally agreed that the enteral route is preferable if possible, but the dangers of the parenteral route, a route of feeding that remains important in the context of critical illness, may have been over-emphasised. Control of hyperglycaemia is beneficial, and avoidance of overfeeding is emphasised. Growth hormone is harmful. The refeeding syndrome needs to be considered, although it has been little studied in the context of critical illness. Achieving energy balance may not be necessary in the early stages of critical illness, particularly in patients who are overweight or obese. Protein turnover is increased and $\mathrm{N}$ balance is often negative in the face of normal nutrient intake; optimal $\mathrm{N}$ intakes are the subject of some debate. Supplementation of particular amino acids able to support or regulate the immune response, such as glutamine, may have a role not only for their potential metabolic effect but also for their potential antioxidant role. Doubt remains in relation to arginine supplementation. High-dose mineral and vitamin antioxidant therapy may have a place.
\end{abstract}

\section{Critical illness: Nutritional support: Metabolic responses: $\mathrm{N}$ and energy balance: Glutamine}

There are 180 adult general critical care units in England, Wales and Northern Ireland that participate in the Intensive Care National Audit and Research Centre Case Mix Programme Database, and analysis of validated data on 129647 admissions to 128 adult critical care units (Harrison et al. 2004) suggests an overall intensive care unit (ICU) mortality of $20.3 \%$ and an in-hospital mortality of $28.6 \%$, which accords well with other national data but varies across countries.

In the UK the prevalence of severe sepsis in the adult ICU is $27.7 \%$, i.e. an estimated 23211 cases per year, and there is a $44.7 \%$ hospital mortality rate associated with severe sepsis, i.e. an estimated 10375 deaths per year (Intensive Care National Audit and Research Centre, Case Mix Programme Database 2001; Intensive Care National
Audit and Research Centre data based on the number of cases identified in the first $24 \mathrm{~h}$ of admission to ICU). Although survival from sepsis has improved a little over time, mortality rates for septic shock are approximately $50 \%$ (Friedman et al. 1998) and for sepsis are 30-50\%. In the USA there are 750000 new cases of sepsis per year, of which 225000 are fatal (Institute of Healthcare Improvement, 2006).

\section{Metabolic aspects}

The critically-ill patient is subject to two principal metabolic responses, the response to starvation and the response to stress. Starvation is signalled by a low circulating

Abbreviation: ICU, intensive care unit.

Corresponding author: Professor Jeremy Powell-Tuck, fax +44 207375 2103, email j.powell-tuck@qmul.ac.uk 
plasma concentration of insulin. As glycogen becomes depleted blood glucose is maintained by gluconeogenesis and the demand on blood glucose is reduced by the adaptation of the brain to ketone oxidation. Ketones rise in the blood because of oxaloacetate depletion and the result is a modest acidosis. Their oxidation drains fat stores, and the consequent decrease in gluconeogenesis reduces protein depletion. The starved body has a low circulating volume and haemo-concentration, a decreased cardiac output and depleted water-soluble vitamins. Refeeding results in an increase in blood insulin, a movement of glucose into the cells that demands phosphorylation and a consequent, sometimes dangerous, drop in circulating phosphate concentrations. In erythrocytes hypophosphataemia suppresses the conversion of triose phosphates (which accumulate) to 1,3-diphosphoglycerate (Travis et al. 1971). The consequent decline in 2,3-diphosphoglycerate alters oxyHb dissociation and results in reduced $\mathrm{O}_{2}$ delivery to the central nervous system, with consequent paraesthesiae and fits. $\mathrm{K}$ and $\mathrm{Mg}$ move intracellularly and concentrations may also drop dangerously in plasma. Refeeding produces an insulin-mediated increase in circulating volume which, superimposed on a wasted heart, risks heart failure. Increased carbohydrate metabolism places demands on B-vitamin requirements in the face of depletion, which may precipitate lactic acidosis, a problem that has been seen particularly in the context of artificial refeeding (Anonymous, 1997).

Stress from sepsis or trauma results in the elaboration of chemokines and pro-inflammatory cytokines and the production of reactive oxygen and nitrogen species (Cohen, 2002). These components combine with prostanoids, thromboxanes and other fatty acid-derived inflammatory mediators, which are also produced, to cause reduced myocardial contractility, impaired peripheral vascular tone and microvascular occlusion, which leads to tissue hypoperfusion, inadequate oxygenation and organ failure. Membrane function is impaired and may result in an amplification of the production of reactive oxygen species, chemokines and cytokines (Fink, 2003). Endocrinologically, cortisol, catecholamines, glucagon and growth hormone dominate. There is also an increase in insulinlike growth factor-binding protein-1 and marked insulin resistance. Lactate production and gluconeogenesis are increased and there is impaired glycogen synthesis. Noninsulin-dependent glucose uptake (GLUT1, GLUT2) is increased and insulin-dependent glucose uptake by the heart, muscle and adipose tissue (GLUT4) is impaired (Van den Berghe, 2004). Maximal rates of glucose oxidation appear to be of the order of $5 \mathrm{mg} / \mathrm{kg}$ per min (Guenst \& Nelson, 1994). Whole-body protein turnover is increased, with protein breakdown exceeding synthesis and resulting in a negative $\mathrm{N}$ balance and wasting. Muscle protein degradation is largely a result of activation of the ubiquitin-proteasome pathway (Wolfe \& Martini, 2000; Wolfe, 2005). Net flow of amino acids away from muscle provides the substrate for increased protein synthesis in the liver, spleen, kidney, jejunum, diaphragm, lung and skin. Altered muscle amino acid transport kinetics may limit the transport of exogenous amino acids into the muscle. Despite this increased flow from the muscle, blood concentrations of glutamine fall, emphasizing increased demands on this amino acid, which is used as a fuel in cells that are rapidly turning over such as lymphocytes and enterocytes. Lipolysis is increased in critical illness to a greater extent than fat oxidation. Provision of fat maintains fat stores but has little effect on the rate of oxidation of plasma NEFA.

\section{Objectives}

The objectives of nutritional support in critical care are to: (1) save life; (2) preserve and improve cellular function; (3) speed recovery.

In the past there has been much emphasis on preventing wasting and therefore improving the rate of recovery. The maintenance of muscle mass to enable early mobility and the prevention of long-term complications such as the neuropathy of critical illness deserve emphasis. Starvation is poorly tolerated against the background of stress-related gluconeogenesis, and dangerous depletion of lean body mass occurs much more quickly than when starvation is uncomplicated by disease. However, prime emphasis must be given to saving life and preserving and improving cellular function. In particular biochemical cofactor availability must be maintained by preventing the deficiency of water-soluble vitamins and care must be taken not to do harm by inappropriate over-feeding. There is increasing evidence that nutritional intake and metabolic management can modify the immune cascades that are fundamental to sepsis and improve outcome.

\section{Insulin and glucose: insulin and maintenance of normoglycaemia}

In patients with diabetes who are suffering acute myocardial infarction the maintenance of blood glucose with insulin and the continued use of insulin for $\geq 3$ months reduces long-term mortality (Malmberg et al. 1995; Malmberg, 1997). Subsequent to this finding, two trials have been conducted in critically-ill patients in surgical (van den Berghe et al. 2001) and medical (Van den Berghe et al. 2006) ICU. In the first trial (van den Berghe et al. 2001) all patients (of whom $13 \%$ had a history of diabetes and $5 \%$ were receiving treatment with insulin) were given a glucose infusion of $200-300 \mathrm{~g}$ in the first $24 \mathrm{~h}$ followed by enteral and/or parenteral nutrition to supply $83 \cdot 4-125 \cdot 1 \mathrm{~kJ}(20-30 \mathrm{kcal}) / \mathrm{kg}$ per $24 \mathrm{~h}$ and $0 \cdot 13-0 \cdot 26 \mathrm{~g}$ $\mathrm{N} / \mathrm{kg}$ per $24 \mathrm{~h}(0.8-1.6 \mathrm{~g}$ protein), with $40 \%$ non-protein energy as lipid. Those patients randomized to receive intensive insulin therapy had their blood glucose maintained between 4.4 and $6.1 \mathrm{mmol} / \mathrm{l}$ for the duration of their ICU stay (not beyond), while control patients only had insulin if their blood glucose was $>11.9 \mathrm{mmol} / \mathrm{l}$ and their blood glucose was maintained between 10 and $11 \mathrm{mmol} / \mathrm{l}$. In-hospital mortality was reduced from $10.9 \%$ to $7.2 \%$ overall $(P<0.01)$ and from $26.3 \%$ to $16.8 \%(P<0.01)$ in those requiring intensive care for $>5 \mathrm{~d}$. This effect arose predominantly from improvements in the outcome of patients undergoing cardiothoracic surgery and seemed to be a result of a reduction in multiple organ failure 
in patients with a proven focus of sepsis. The second study (Van den Berghe et al. 2006) was conducted in 1200 patients treated in a medical ICU and excluded those who could take food by mouth and who were expected to stay on the ICU $<3 \mathrm{~d}$. Enteral feeding was started as early as possible. Control patients received insulin only if their blood glucose was $>12 \mathrm{mmol} / \mathrm{l}$, and patients randomized to intensive insulin therapy received insulin if their blood glucose was $>6 \cdot 1 \mathrm{mmol} / 1$ during the ICU stay only. Hospital mortality was not reduced overall (40\% for the conventional-treatment group, $37 \%$ for the intensiveinsulin-therapy group), but was reduced among patients receiving intensive insulin therapy for $>3 \mathrm{~d}$ on the ICU $(52.5 \%$ v. $43 \%, P=0.009)$. This effect was principally in patients with no history of diabetes. Among 433 patients who were treated on the ICU for $<3 \mathrm{~d}$ fifty-six in the intensive-insulin-therapy group and forty-two of the conventionally-treated group died, a difference that was of borderline significance.

\section{Gastric emptying and intestinal aspects}

Critical illness results in delayed gastric emptying in about $50 \%$ of mechanically-ventilated patients and in most patients with raised intracranial pressure after head injury (Ritz et al. 2000, 2001). It may also have effects on colonic and small intestinal motility. Motility is affected by the disease state, endotoxin and inflammatory mediators, autonomic nervous function, circulating peptides, drugs, surgical procedures and feed and feeding technique. Upper intestinal stasis may allow upper intestinal bacterial colonization with attendant risks of nosocomial infection.

Changes in intestinal motility are the principal reasons why enteral nutrition is sometimes not possible in critical illness. High-output intestinal fistulas or intestinal obstruction pending surgery may make enteral nutrition impossible or impractical. A diffuse dilatation of the intestine, small bowel and/or colon (Delgado-Aros \& Camilleri, 2003) may be seen more rarely. This condition represents an acute intestinal pseudo-obstruction, or Ogilvie's syndrome, and may also be an indication for parenteral nutrition.

In the context of continuous feeding antro-pyloric pressure waves are reduced and there is antral hypomotility, phase III interdigestive motor activity may be absent and postprandial patterns of motility may not occur, an effect that may depend to some extent on the rate and energy content of the feed infusion (Benson \& Wingate, 1993; Benson et al. 1994; CT Soulsby, unpublished results). This failure to convert to a fed pattern of motility may also be seen with post-pyloric feeding, when increased pyloric tone may also be a factor. Measuring gastric emptying during enteral feeding in critically-ill patients is difficult, although use of multi-frequency impedance tomography looks promising in this respect (Soulsby et al. 2006). In the absence of a rigorous measure of gastric emptying, feeds are usually given continuously rather than by bolus and are monitored by naso-gastric aspiration at intervals of $4 \mathrm{~h}$ to prevent large volumes accumulating in the stomach and the risk of vomiting or regurgitation resulting in tracheal aspiration. The position of tubes in the stomach must be regularly monitored, daily or more frequently, by checking the $\mathrm{pH}$ of gastric aspirates with $\mathrm{pH}$ paper (not litmus). Auscultation of an injected bolus of air is not recommended for this purpose. Plain $\mathrm{X}$-rays are commonly carried out during critical illness and may provide supplementary information where $\mathrm{pH}$ paper testing is inconclusive. Once the position of the naso-gastric tube has been verified to be in the stomach it is strongly advised that an indelible mark is placed on the tube close to its exit from the patient's nostril, so that displacement is readily noticed and acted on.

\section{Early $v$. late, enteral $v$. parenteral}

Canadian guidelines for feeding mechanically-ventilated critical-care patients have been drawn up on the basis of a series of systematic reviews (Heyland et al. 2003). Analysis of eight randomized controlled trials suggests that early (first 24-48 h of intensive care) enteral feeding is likely to reduce mortality compared with the alternative strategy of delay. Enteral nutrition is consistently associated with reduced infectious complications compared with parenteral nutrition, but has not been shown to reduce mortality more than parenteral nutrition, which has also been demonstrated in another meta-analysis (Marik \& Zaloga, 2001). Postpyloric feeding is more difficult to achieve and conveys no routine advantage over gastric feeding (Marik \& Zaloga, 2003). Early gastric feeding is therefore recommended, and this strategy gains support from the trends to improved outcome seen in the Algorithms for CriticalCare Enteral and Parenteral Therapy trial (Martin et al. 2004). If early gastric feeding is not possible or desirable then three options emerge: to delay; to feed postpylorically or to feed parenterally. A recent meta-analysis shows that parenteral nutrition reduces mortality compared with delay (Simpson \& Doig, 2005) but trans-pyloric feeding is similarly effective. Thus, the decision to feed parenterally or post-pylorically in this situation can be decided on practical and economic grounds, which are likely to vary from unit to unit, and balance the expense of parenteral feeds against the organisational costs of providing repeated endoscopies on an ICU outside the endoscopy facilities.

Overall experience at the Royal London Hospital, London, UK suggests that parenteral nutrition becomes necessary in approximately $10-20 \%$ of the patients on a mixed medical and surgical ICU, which is consistent with Canadian practice (Heyland et al. 2004). A 1999 European survey (Preiser et al. 1999) has shown wide variation in practice, with a median $23 \%$ of patients receiving parenteral nutrition alone and $19 \%$ receiving enteral and parenteral feeding simultaneously.

\section{Energy intake}

Excess energy input results in increased $\mathrm{CO}_{2}$ output and increased levels of stress hormones. In recent years emphasis has been placed on the dangers of the refeeding 
syndrome, with heart failure, hypophosphataemia, hypokalaemia, hypomagnesaemia and acute B-vitamin deficiency (Hearing, 2004; Korbonits et al. 2005), most of which seem to relate to a sudden switch from a low to a high insulin state. While it is clearly wise to replenish water-soluble vitamin stores, the dangers of the refeeding syndrome in the context of high-insulin stress-related insulin resistance need further study. Insulin resistance occurs in many critically-ill patients and it is not clear whether they are at as great a risk of refeeding syndrome as those in whom insulin resistance is less marked. Hypophosphataemia occurs if glucose infusions are given in the post-operative phase (Hessov et al. 1980), and refeeding hypophosphataemia is common in mixed medical and surgical ICU (Marik \& Bedigian, 1996). The insulin and glucose regimen used by van den Berghe et al. (2001) in the intensive insulin therapy group of the surgical trial might have been expected to increase risks of hypophosphataemia and hypokalaemia but was associated with a good outcome. The medical study (Van den Berghe et al. 2006) did not use glucose loading, but nevertheless the increased insulin input might have been expected to increase the refeeding effect, an effect that would be expected early in the course of nutritional treatment. For the time being, caution is recommended. Furthermore, glucose infusions should not exceed maximum rates of oxidation or $4 \mathrm{mg} / \mathrm{kg}$ per min in order not to result in lipid synthesis and increased $\mathrm{CO}_{2}$ output (Guenst \& Nelson, 1994). Phosphate, $\mathrm{K}$ and $\mathrm{Mg}$ levels should be closely monitored during artificial feeding in an ICU. In general, it seems safer to feed these patients at levels of energy close to, or marginally higher than, the BMR predicted by Schofield (1985) tables, and to start at lower intakes. Precise recommendations for intake cannot be made on the basis of outcome evidence.

\section{Protein intake}

There are few data that analyse intake in relation to clinical outcome and thus guide the optimal protein or $\mathrm{N}$ intake during nutritional support of the critically-ill patient. One study (Collins et al. 1998) that was conducted in starving Somalian patients with an average weight of $34 \mathrm{~kg}$ suggests that avoiding a high protein intake (156 g protein/d) and giving a more modest amount $(81 \mathrm{~g} / \mathrm{d}$ or approximately $2.4 \mathrm{~g}$ protein $/ \mathrm{kg}$ per d) could reduce mortality in oedematous patients in a famine-relief setting. However, although this study compared isoenergetic feeds, the lower-protein feed contained more fat and less carbohydrate. Since the refeeding syndrome is a result of increased insulinaemia, it seems most likely that the results of this trial are explained on the basis of a high-fat feed reducing risks of refeeding in the transition between the starving fat-based metabolism to the fed state compared with an isoenergetic higher-carbohydrate feed. Nevertheless, the lower protein intake would have been regarded as high by the standards of most intensive care specialists. However, this paper does not relate to critical illness as seen in ICU in the developed world.

In one animal model of sepsis the restriction of protein appeared beneficial (Peck et al. 1989), whereas in another species protein restriction appeared harmful (Peck et al. 1992). Rat studies suggest that hypoenergetic (Raina et al. 1999) feeds and high-protein diets (Raina \& Jeejeebhoy, 2004) reduce TNF- $\alpha$ expression. In patients with burns there is evidence in children (Alexander et al. 1980) of benefit from increasing $\mathrm{N}$ intakes from $0.61 \mathrm{~g} / \mathrm{kg}$ per $\mathrm{d}$ to $0.79 \mathrm{~g} / \mathrm{kg}$ per $\mathrm{d}$, with a significant reduction in mortality from five of nine $(44 \%)$ to none of nine $(0 \%$; $P<0 \cdot 03)$.

Intakes of $1-1.5 \mathrm{~g}$ protein $(0 \cdot 16-0 \cdot 24 \mathrm{~g} \mathrm{~N}) / \mathrm{kg}$ per $\mathrm{d}$ are common practice and usually advised. One study (Shaw et al. 1983) suggests that $1.5 \mathrm{~g}$ protein $/ \mathrm{kg}$ per $\mathrm{d}$ is optimal in nutritionally-depleted patients receiving parenteral nutrition but several studies (Wolfe et al. 1983; Cerra et al. 1987) have shown that higher intakes can improve $N$ retention in patients with burns (Wolfe et al. 1983) and in stress associated with trauma and sepsis (Cerra et al. 1987). Hoffer (2003) has argued that reducing energy provision in critical care may require an increase in protein intake to $>1.5 \mathrm{~g}$ protein $/ \mathrm{kg}$ per $\mathrm{d}$.

Hyperinsulinaemia in normal individuals results in depression of some precursors, particularly branchedchain amino acid pools, secondary to a reduction in protein breakdown, with a consequent reduction in wholebody protein synthesis (Castellino et al. 1987). The adoption of tight glycaemic control with early use of insulin may therefore have implications for protein input. The studies in the author's group performed over many years on the effect of insulin on protein turnover during parenteral nutrition are summarized elsewhere (Powell-Tuck, 2000). Of particular relevance here is a study (Glynn et al. 1987) of six stable parenterallyfed patients with severe post-operative sepsis, of whom five needed ventilatory support, that compared protein turnover during tight glycaemic control (blood glucose 4$6 \mathrm{mmol} / \mathrm{l})$ with standard glycaemic control $(8-10 \mathrm{mmol} / \mathrm{l})$ in a randomized cross-over design. These patients were receiving a mean $\mathrm{N}$ intake of $288.4 \mathrm{mg} / \mathrm{kg}$ per $24 \mathrm{~h}$ in nutritionally-complete mixtures. No enhanced $\mathrm{N}$ balance was found with tight glycaemic control and no change in excretion of 3-methylhistidine, a valid measure of protein breakdown on this constant artificial feed. No change was observed in whole-body protein turnover, synthesis or breakdown as glycaemia and insulinaemia was varied in these patients, in contrast with studies by the author's group (Ang et al. 1992, 2000) and other groups (Castellino et al. 1987) in parenterally-fed normal subjects.

The debate over optimal intakes of protein with or without insulin in critically-ill patients with sepsis may be misleading. It is likely that under these conditions requirements for some amino acids become abnormally high relative to others and may not be easily met using even high-quality protein. Thus, requirements for $\mathrm{S}$ containing amino acids, glutamine and other precursors for glutathione such as glycine may be increased relative to other nutrients (Grimble, 2001). The next section will discuss glutamine, and here the large amounts that have been advocated will, in practice, substantially increase total $\mathrm{N}$ intakes, which may not be meaningfully translated to protein equivalents. 


\section{Gut mucosal barrier and its relationship to sepsis, systemic inflammatory response syndrome and multiple organ failure}

The intestinal mucosa provides a barrier between bacteria and bacterial products in the intestinal lumen and the body's circulation and organs. It is proposed that a derangement of this barrier function occurs during critical illness that results in the amplification of the general inflammatory response and predisposes to multiple organ failure (Fink, 2003; De-Souza \& Greene, 2005).

This outcome might be a result of: (1) translocation of bacteria into the blood circulation, which is detectable by culture or by detecting their DNA; (2) translocation of bacterial products or antigens into the systemic circulation or (3) amplification of an abnormal intestinal proinflammatory response, with release of pro-inflammatory cytokines etc. into the circulation in response to normal or abnormal lumen bacteria.

The intestinal mucosa and the lamina propria contain large numbers of immune cells that interact with each other and with the lumen milieu. The pathogenesis of gut mucosal barrier dysfunction in critical illness has been well summarized (Fink, 2003). Partially-reduced derivatives of molecular oxygen, superoxide, $\mathrm{H}_{2} \mathrm{O}_{2}$ and hydroxyl radicals are important mediators of inflammation, and oxidant stress increases the permeability of intestinal monolayers, depletes intracellular ATP and inhibits $\mathrm{Na}^{+}-\mathrm{H}^{+}$exchange. Oxidant stress-related abnormalities in permeability may relate particularly to which of the protein kinase $\mathrm{C}$ isoforms are expressed or activated, with protein kinase $\mathrm{C}-\delta$ essential for this effect.

Studies of hypoxia support the concept that depletion of cellular ATP increases paracellular permeability. Stimulation of cells by pro-inflammatory cytokines amplifies cellular elaboration of other cytokines and the combined effects result in an increased mucosal permeability via NO synthase mRNA induction. Anti-inflammatory cytokines have the opposite effect. IL-6 appears necessary for the effect of sepsis on intestinal permeability in mice. NO can be both protective and damaging. Toxic effects are thought to be mediated via the peroxynitrite anion, with permeability effects mediated via Na-K ATPase inhibition. An overall picture emerges of a large and cellular organ responding to stress and in doing so altering its interaction with the lumen contents, with the potential for huge and harmful amplification of the inflammatory response not just in the intestine but throughout the rest of the body.

\section{Glutamine}

Glutamine is the amino acid constituent of human protein found in highest concentrations in the plasma and in the cells. It is the principal fuel of enterocytes and lymphocytes. Glutamine is formed in muscle from the catabolism of branched-chain amino acids. Muscle cell concentrations (about $25 \mathrm{mmol} / \mathrm{l}$ ) are far higher than plasma levels (about $650 \mu \mathrm{mol} / \mathrm{l}$ ), which is related to a saturable Na-linked hormone- and endotoxin-sensitive cotransporter mechanism (Rennie et al. 1986, 1996). Plasma and intramuscular glutamine concentrations drop during metabolic stress such as surgery, trauma, infection and sepsis to levels of approximately $300-500 \mu \mathrm{mol} / 1$ and $15 \mathrm{mmol} / \mathrm{l}$ respectively. It remains unclear to what extent this drop in concentration affects the metabolism and function of the intestinal mucosa, particularly in the presence of an existing inflammatory response.

Previous studies in normal subjects have shown that infusions of about $1 \mathrm{~g}$ glutamine (as the dipeptide)/h for a $70 \mathrm{~kg}$ man can result in increases in arterial concentration from $620 \mu \mathrm{mol} / 1$ to $764 \mu \mathrm{mol} / \mathrm{l}$ (Lochs et al. 1990). Wernerman and his colleagues (Tjader et al. 2004) have shown that in stressed human subjects infusions of $20-40 \mathrm{~g} / 24 \mathrm{~h}$ usually achieve venous plasma levels of $\geq 500 \mu \mathrm{mol} / 1$, but to achieve $\geq 6 \mu \mathrm{mol} / \mathrm{l}$ consistently can require infusions of $40-60 \mathrm{~g} / 24 \mathrm{~h}$. This finding is consistent with data (PowellTuck et al. 1999) in patients that show modest rises with infusions of only $20 \mathrm{~g}$ glutamine $/ 24 \mathrm{~h}$. Doses of intravenous glutamine of $\leq 0.57 \mathrm{~g} / \mathrm{kg}$ body weight per $24 \mathrm{~h}$ have been shown to produce plasma glutamine plateaux that are about $25 \%$ above control values in normal subjects without increases in potentially-toxic metabolites $\mathrm{NH}_{3}$ and glutamate (Lowe et al. 1990).

Glutamine has been shown previously to maintain intestinal cell layer barrier function, suppress an acetaldehyde-induced increase in paracellular permeability in cell monolayers, (Seth et al. 2004; Basuroy et al. 2005), down regulate cell line $\mathrm{CXC}$ chemokines, down regulate cytokine production (Coeffier et al. 2001; Liboni et al. 2004) and enhance haemoxygenase- 1 expression in the duodenal mucosa (Coeffier et al. 2002). Glutamine deprivation increases TNF-induced bacterial translocation in Caco-2 cells (Clark et al. 2003) and regulates tightjunction proteins, claudin-1, occludin and ZO-1 ( Li et al. 2004). However, studies in cell lines have not examined the effects of change in glutamine concentration seen pathophysiologically in human subjects.

\section{Glutamine as an antioxidant}

Glutamine through glutamate is a glutathione precursor. Glutathione is an important intracellular antioxidant. Glutamine infusion can result in enhanced tissue glutathione levels and enhanced antioxidant capacity (Wernerman \& Hammarqvist, 1999; Mates et al. 2002; Flaring et al. 2003; Wessner et al. 2003; Hammarqvist et al. 2005; Humbert et al. 2006).

\section{Glutamine and its effect on heat-shock proteins}

Heat-shock proteins are 'cellular chaperones' involved in the management of stress-induced protein unfolding and apoptosis. Their role as fundamental mediators of some of the biological effects of glutamine has been reviewed recently (Wischmeyer, 2006). Glutamine depletion results in diminished synthesis of heat-shock proteins (Eliasen et al. 2006). Enteral glutamine increases duodenal haemoxygenase- 1 in human subjects (Coeffier et al. 2002) and the glutamine effect on cell survival has been shown to be specific to heat-shock protein-1 in mouse fibroblasts. Recently, glutamine dipeptide infusion has been shown to 
increase heat-shock protein-70 approximately fourfold in critical illness (Ziegler et al. 2005).

Glutamine has been used in both enteral and parenteral feeds, and parenteral glutamine has emerged in metaanalysis in critical illness as possibly the most effective in reducing mortality (Novak et al. 2002; Avenell, 2006). One study in patients with burns (Wischmeyer et al. 2001) has used parenteral glutamine independently of the method of feed administration with good effect on infectious complications. This approach to parenteral administration independent of the route of feeding appears very promising and needs testing in a wider critical-care setting.

\section{Arginine-containing feeds}

Arginine is a $\mathrm{C}_{5}$ basic amino acid that plays a central role in the immune system. It is a principal precursor for NO synthesis (with the formation of citrulline) and functions as a secretagogue for a number of hormones including growth hormone and prolactin. Arginine can participate in a systemic inflammatory response, first through the production of NO and second through utilization for T lymphocyte and macrophage function and proliferation.

A recent review (Bansal \& Ochoa, 2003) has compared the initial systemic inflammatory response signalled by cytokines IL-1, IL-2, $\gamma$-interferon and TNF with the subsequent down-regulation of the immune response (compensatory anti-inflammatory response) signalled by IL-4, -10 and -13. In inflammatory response syndrome inducible NO synthase increases NO production from arginine in macrophages, and arginine is used for T-cell function and proliferation. In compensatory antiinflammatory response syndrome one or both arginase isoforms are up regulated in macrophages, which can modulate the inflammatory response by: (1) producing ornithine, thus enhancing wound healing; (2) producing polyamines from ornithine that support macrophage function; (3) metabolic redirection, reducing arginine availability for NO synthesis (Bansal \& Ochoa, 2003). Trials of the effect of free arginine on clinical outcome are lacking; clinical controlled trials have used 'immuneenhancing' enteral feeds that combine arginine with other nutriceuticals such as antioxidants, glutamine, antiinflammatory fatty acids and nucleotides. Most of the clinical trials have employed mixtures of these nutrients in enteral feeds. Since these mixtures vary, results can be difficult to analyse. Meta-analyses have been performed but provide different interpretations dependent on which trials are included and which trials are taken together. 'Immunonutrition' feeds tend to be associated with a lower number of infectious complications (risk ratio 0.66 $(95 \%$ CI $0.54,0.80)$ ) and a shorter length of hospital stay (Heyland et al. 2001), most notably in interventions that used a high content of arginine. However, the same meta-analysis drew attention to the higher mortality associated with immunonutrition in trials with high (good) methodological scores. At present, routine use cannot be recommended in critical care.

\section{Antioxidants}

Oxidant stress is increased in critical illness and can be assessed by measuring a number of markers (Roth et al. 2004); a commonly employed technique is to measure byproducts of oxidative damage of lipids (thiobarbituricreacting substances) by the malondialdehyde assay. High oxidant stress is associated with poor outcome (Motoyama et al. 2003; Mishra et al. 2005). As discussed earlier such oxidant stress can be viewed as pivotal to a gradual amplification of the generalized immune response to the point where it becomes harmful and progresses to multiple organ failure. The use of large doses of antioxidants might prevent this outcome. In critically-ill patients who have undergone surgery (Nathens et al. 2002) a combination of $\alpha$-tocopherol and ascorbic acid reduces the risk of developing multiple organ failure. Other antioxidants that have been employed include $\mathrm{N}$-acetylcysteine, vitamin $\mathrm{A}$ and Se. A meta-analysis (Heyland et al. 2005) of eleven randomized clinical trials has demonstrated a reduction in mortality but not infectious complications when antioxidants are tested in critical illness; high-dose parenteral Se appears to emerge as the most effective. It is of interest to note that Se could, through glutathione peroxidase activation, enhance the clinical effect of glutamine.

\section{Selenium}

Enzymes such as superoxide dismutase, catalase and gluthathione peroxidase protect against reactive oxygen species. Se is a critical cofactor in the activity of gluthathione peroxidase, and is also important in the management of peroxynitrite.

The acute-phase response can reduce circulating levels of Se via redistribution out of the bloodstream (Forceville et al. 1998; Berger et al. 2001). Although acutely-ill patients are presumed to be free of previous deficiency at the time of presentation, studies have shown that the $\mathrm{Se}$ status is suboptimal in a large portion of the population in various European countries (Rayman, 2000). Most studies recommend a Se level of $160 \mu \mathrm{g} / \mathrm{l}$ in whole blood and $135 \mu \mathrm{g} / \mathrm{l}$ in serum; however, the ideal blood Se level has not yet been established. The current WHO recommendation (World Health Organization/Food and Agriculture Organization, 2004) for the safe maximum long-term intake of Se is $400 \mu \mathrm{g} / \mathrm{d}$, which is applicable to healthy individuals who have no symptoms of Se deficiency and are not under conditions of increased stress. In individuals with disorders associated with excessive free radical production such as trauma, higher intakes may be beneficial.

Various doses of Se have been prescribed in clinical trials. A dose of $500 \mu \mathrm{g} / \mathrm{d}$ has been shown to reduce the need for haemodialysis in patients with systemic inflammatory response syndrome (Angstwurm et al. 1999; Berger \& Chiolero, 1995) and reduce pulmonary infections in patients with burns (Berger et al. 1998). Meta-analyses of Se-supplementation trials in critical illness (Avenell et al. 2004) have demonstrated a reduction in mortality and that studies that have used $\mathrm{Se}$ doses higher than the median dose $(500-1000 \mu \mathrm{g} / \mathrm{d})$ are associated with a trend towards reduced mortality (Heyland et al. 2005), whereas 
studies that have used a dose less than the median dose $(<500 \mu \mathrm{g} / \mathrm{d})$ have found no effect on mortality. Studies of patients with burns and systemic inflammatory response syndrome have shown that without supplementation $\mathrm{Se}$ levels can be depleted for a period of 10-14 d.

\section{Conclusion}

Nutritional support should be provided early in critical care, by the naso-gastric route if possible or by the postpyloric or parenteral routes if not. Feeding should be cautious and care taken not to complicate an already complicated metabolic state with a refeeding syndrome scenario. Particular care should be taken over the delivery of energy, where it is better to underfeed than to strive to provide every last kilojoule. There is debate about how much protein to provide but the author tends to encourage a generous protein intake of between 1 and $1.5 \mathrm{~g}$ protein $/ \mathrm{kg}$ per d, or slightly more. The provision of glutamine and antioxidants may be beneficial and is an exciting area of practice development, but formal proof that antioxidants reduce mortality is still lacking, although meta-analyses are encouraging.

\section{Acknowledgements}

This paper emerges from collaborations with my colleagues Miss Clare Soulsby, Drs Simon Eaton, Danny McAuley, Margaret Rayman and Michael Geoghegan, whose valuable discussions and input are gratefully acknowledged.

\section{References}

Alexander JW, MacMillan BG, Stinnett JD, Ogle CK, Bozian RC, Fischer JE, Oakes JB, Morris MJ \& Krummel R (1980) Beneficial effects of aggressive protein feeding in severely burned children. Annals of Surgery 192, 505-517.

Ang B, Wade A, Halliday D \& Powell-Tuck J (2000) Insulin reduces leucine oxidation and improves net leucine retention in parenterally fed humans. Nutrition 16, 221-225.

Ang BCN, Halliday D, Wade AJ \& Powell-Tuck J (1992) Insulin reduces leucine oxidation and improves nitrogen balance in the parenterally fed state. Proceedings of the Nutrition Society 51, $111 \mathrm{~A}$.

Angstwurm MW, Schottdorf J, Schopohl J \& Gaertner R (1999) Selenium replacement in patients with severe systemic inflammatory response syndrome improves clinical outcome. Critical Care Medicine 27, 1807-1813.

Anonymous (1997) Lactic acidosis traced to thiamine deficiency related to nationwide shortage of multivitamins for total parenteral nutrition-United States 1997. Morbidity and Mortality Weekly Report 46, 523-528.

Avenell A (2006) Glutamine in critical care: current evidence from systematic reviews. Proceedings of the Nutrition Society 65, 236-241.

Avenell A, Noble DW, Barr J \& Engelhardt T (2004) Selenium supplementation for critically ill adults. The Cochrane Database of Systematic Reviews 2004, issue 4, CD003703. Chichester, West Sussex: John Wiley \& Sons Ltd.
Bansal V \& Ochoa JB (2003) Arginine availability, arginase, and the immune response. Current Opinion in Clinical Nutrition and Metabolic Care 6, 223-228.

Basuroy S, Sheth P, Mansbach CM \& Rao RK (2005) Acetaldehyde disrupts tight junctions and adherens junctions in human colonic mucosa: protection by EGF and L-glutamine. American Journal of Physiology 289, G367-G375.

Benson MJ, Roberts JP, Wingate DL, Rogers J, Deeks JJ, Castillo FD \& Williams NS (1994) Small bowel motility following major intra-abdominal surgery: the effects of opiates and rectal cisapride. Gastroenterology 106, 924-936.

Benson MJ \& Wingate DL (1993) Ileus and mechanical obstruction. In An Illustrated Guide to Gastrointestinal Motility, pp. 547-566 [D Kumar and D Wingate, editors]. Edinburgh: Churchill Livingstone.

Berger MM \& Chiolero R (1995) Relations between copper, zinc and selenium intakes and malondialdehyde excretion after major burns. Burns 21, 507-512.

Berger MM, Reymond MJ, Shenkin A, Rey F, Wardle C, Cayeux C, Schindler C \& Chiolero RL (2001) Influence of selenium supplements on the post-traumatic alterations of the thyroid axis: a placebo-controlled trial. Intensive Care Medicine 27, 91-100.

Berger MM, Spertini F, Shenkin A, Wardle C, Wiesner L, Schindler C \& Chiolero RL (1998) Trace element supplementation modulates pulmonary infection rates after major burns: a double-blind, placebo-controlled trial. American Journal of Clinical Nutrition 68, 365-371.

Castellino P, Luzi L, Simonson DC, Haymond M \& DeFronzo RA (1987) Effect of insulin and plasma amino acid concentration on leucine metabolism: role of substrate availability on estimates of whole body protein synthesis. Journal of Clinical Investigation 80, 1784-1793.

Cerra F, Blackburn G, Hirsch J, Mullen K \& Luther W (1987) The effect of stress level, amino acid formula, and nitrogen dose on nitrogen retention in traumatic and septic stress. Annals of Surgery 205, 282-287.

Clark EC, Patel SD, Chadwick PR, Warhurst G, Curry A \& Carlson GL (2003) Glutamine deprivation facilitates tumour necrosis factor induced bacterial translocation in Caco-2 cells by depletion of enterocyte fuel substrate. Gut $\mathbf{5 2}$, 224-230.

Coeffier M, Le Pessot F, Leplingard A, Marion R, Lerebours E, Ducrotte P \& Dechelotte P (2002) Acute enteral glutamine infusion enhances heme oxygenase-1 expression in human duodenal mucosa. Journal of Nutrition 132, 2570-2573.

Coeffier M, Miralles-Barrachina O, Le Pessot F, Lalaude O, Daveau M, Lavoinne A, Lerebours E \& Dechelotte P (2001) Influence of glutamine on cytokine production by human gut in vitro. Cytokine 13, 148-154.

Cohen J (2002) The immunopathogenesis of sepsis. Nature 420 , 885-891.

Collins S, Myatt M \& Golden B (1998) Dietary treatment of severe malnutrition in adults. American Journal of Clinical Nutrition 68, 193-199.

Delgado-Aros S \& Camilleri M (2003) Pseudo-obstruction in the critically ill. Best Practice and Research Clinical Gastroenterology 17, 427-444.

De-Souza DA \& Greene LJ (2005) Intestinal permeability and systemic infections in critically ill patients: effect of glutamine. Critical Care Medicine 33, 1125-1135.

Eliasen MM, Brabec M, Gerner C, Pollheimer J, Auer H, Zellner M, Weingartmann G, Garo F, Roth E \& Oehler R (2006) Reduced stress tolerance of glutamine-deprived human monocytic cells is associated with selective down-regulation of Hsp70 by decreased mRNA stability. Journal of Molecular Medicine 84, 147-158. 
Fink MP (2003) Intestinal epithelial hyperpermeability: update on the pathogenesis of gut mucosal barrier dysfunction in critical illness. Current Opinion in Critical Care $\mathbf{9}$, $143-151$.

Flaring UB, Rooyackers OE, Wernerman J \& Hammarqvist F (2003) Glutamine attenuates post-traumatic glutathione depletion in human muscle. Clinical Science 104, 275-282.

Forceville X, Vitoux D, Gauzit R, Combes A, Lahilaire P \& Chappuis P (1998) Selenium, systemic immune response syndrome, sepsis and outcome in critically ill patients. Critical Care Medicine 26, 1536-1544.

Friedman G, Silva E \& Vincent JL (1998) Has the mortality of septic shock changed with time. Critical Care Medicine 26, 2078-2086.

Glynn MJ, Metzner S, Halliday D \& Powell-Tuck J (1987) The effect of exogenous insulin on whole body protein metabolism during the total parenteral nutrition of critically ill intensive care patients. Clinical Nutrition 6, Suppl. 1, 45.

Grimble RF (2001) Stress proteins in disease: metabolism on a knife edge. Clinical Nutrition 20, 469-476.

Guenst JM \& Nelson LD (1994) Predictors of total parenteral nutrition-induced lipogenesis. Chest 105, 553-559.

Hammarqvist F, Andersson K, Luo JL \& Wernerman J (2005) Free amino acid and glutathione concentrations in muscle during short-term starvation and refeeding. Clinical Nutrition 24, 236-243.

Harrison DA, Brady AR \& Rowan K (2004) Case mix, outcome and length of stay for admissions to adult, general critical care units in England, Wales and Northern Ireland: the Intensive Care National Audit \& Research Centre Case Mix Programme Database. Critical Care 8, R99-R111; available at http://ccforum.com/content/8/2/R99

Hearing SD (2004) Refeeding syndrome. British Medical Journal 328, 908-909.

Hessov I, Jensen NG \& Rasmussen A (1980) Prevention of hypophosphatemia during postoperative routine glucose administration. Acta Chirurgica Scandinavica 146, 109-114.

Heyland DK, Dhaliwal R, Day A, Jain M \& Drover J (2004) Validation of the Canadian clinical practice guidelines for nutrition support in mechanically ventilated, critically ill adult patients: results of a prospective observational study. Critical Care Medicine 32, 2260-2266.

Heyland DK, Dhaliwal R, Drover JW, Gramlich L \& Dodek P (2003) Canadian clinical practice guidelines for nutrition support in mechanically ventilated, critically ill adult patients. Journal of Parenteral and Enteral Nutrition 27, 355-373.

Heyland DK, Dhaliwal R, Suchner U \& Berger MM (2005) Antioxidant nutrients: a systematic review of trace elements and vitamins in the critically ill patient. Intensive Care Medicine 31, 327-337.

Heyland DK, Novak F, Drover JW, Jain M, Su X \& Suchner U (2001) Should immunonutrition become routine in critically ill patients? A systematic review of the evidence. Journal of the American Medical Association 286, 944-953.

Hoffer LJ (2003) Protein and energy provision in critical illness. American Journal of Clinical Nutrition 78, 906-911.

Humbert B, Nguyen P, Martin L, Dumon H, Vallette G, Maugère P \& Darmaun D (2006) Effect of glutamine on glutathione kinetics in vivo in dogs. Journal of Nutritional Biochemistry 18, 10-16.

Institute of Healthcare Improvement (2006) Sepsis care enters new era. http://www.ihi.org/IHI/Topics/CriticalCare/ Sepsis/ImprovementStories/SepsisCareEntersNewEra.htm

Korbonits M, Blaine D, Elia M \& Powell-Tuck J (2005) Refeeding David Blaine - studies after a 44-day fast. New England Journal of Medicine 353, 2306-2307.
Li N, Lewis P, Samuelson D, Liboni K \& Neu J (2004) Glutamine regulates Caco-2 cell tight junction proteins. American Journal of Physiology 287, G726-G733.

Liboni K, Li N \& Neu J (2004) Mechanism of glutaminemediated amelioration of lipopolysaccharide-induced IL-8 production in Caco-2 cells. Cytokine 21, 57-65.

Lochs H, Roth E, Gasic S, Hubl W, Morse EL \& Adibi SA (1990) Splanchnic, renal, and muscle clearance of alanylglutamine in man and organ fluxes of alanine and glutamine when infused in free and peptide forms. Metabolism 39, 833-836.

Lowe DK, Benfell K, Smith RJ, Jacobs DO, Murawski B, Ziegler TR \& Wilmore DW (1990) Safety of glutamine-enriched parenteral nutrient solutions in humans. American Journal of Clinical Nutrition 52, 1101-1106.

Malmberg K (1997) Prospective randomised study of intensive insulin treatment on long term survival after acute myocardial infarction in patients with diabetes mellitus. DIGAMI (Diabetes Mellitus Insulin Glucose Infusion in Acute Myocardial Infarction) Study Group. British Medical Journal 314, 1512-1515.

Malmberg K, Ryden L, Efendic S, Herlitz J, Nicol P, Waldenstrom A, Wedel H \& Welin L (1995) Randomized trial of insulin-glucose infusion followed by subcutaneous insulin treatment in diabetic patients with acute myocardial infarction (DIGAMI study): effects on mortality at 1 year. Journal of the American College of Cardiology 26, 57-65.

Marik PE \& Bedigian MK (1996) Refeeding hypophosphatemia in critically ill patients in an intensive care unit. A prospective study. Archives of Surgery 131, 1043-1047.

Marik PE \& Zaloga GP (2001) Early enteral nutrition in acutely ill patients: a systematic review. Critical Care Medicine 29, 2264-2270.

Marik PE \& Zaloga GP (2003) Gastric versus post-pyloric feeding: a systematic review. Critical Care 7, R46-R51.

Martin CM, Doig GS, Heyland DK, Morrison T \& Sibbald WJ (2004) Multicentre, cluster-randomized clinical trial of algorithms for critical-care enteral and parenteral therapy (ACCEPT). Canadian Medical Association Journal 170, 197-204.

Mates JM, Perez-Gomez C, de Castro INV, Asenjo M \& Marquez J (2002) Glutamine and its relationship with intracellular redox status, oxidative stress and cell proliferation/death. International Journal of Biochemistry and Cell Biology 34, 439-458.

Mishra V, Baines M, Wenstone R \& Shenkin A (2005) Markers of oxidative damage, antioxidant status and clinical outcome in critically ill patients. Annals of Clinical Biochemistry 42, 269-276.

Motoyama T, Okamoto K, Kukita I, Hamaguchi M, Kinoshita Y \& Ogawa H (2003) Possible role of increased oxidant stress in multiple organ failure after systemic inflammatory response syndrome. Critical Care Medicine 31, 1048-1052.

Nathens AB, Neff MJ \& Jurkovich GJ (2002) Randomized, prospective trial of antioxidant supplementation in critically ill surgical patients. Annals of Surgery 236, 814-822.

Novak F, Heyland DK, Avenell A, Drover JW \& Su X (2002) Glutamine supplementation in serious illness: a systematic review of the evidence. Critical Care Medicine 30, 2022-2029.

Peck MD, Alexander JW, Gonce SJ \& Miskell PW (1989) Low protein diets improve survival from peritonitis in guinea pigs. Annals of Surgery 209, 448-454.

Peck MD, Babcock GF \& Alexander JW (1992) The role of protein and calorie restriction in outcome from Salmonella infection in mice. Journal of Parenteral and Enteral Nutrition 16, 561-565.

Powell-Tuck J (2000) The manipulation of plasma insulin concentration during clinical nutrition support: clinical application of protein turnover measurements. In Nutritional 
Metabolism and Malnutrition: A Festschrift for John Conrad Waterlow, pp. 81-86 [P Shetty, editor]. London: Smith-Gordon.

Powell-Tuck J, Jamieson CP, Bettany GEA, Obeid O, Fawcett HV, Archer C \& Murphy DL (1999) A double blind, randomised controlled trial of glutamine supplementation in parenteral nutrition. Gut 45, 82-88.

Preiser JC, Berre J, Carpentier Y, Jolliet P, Pichard C, Van Gossum A \& Vincent JL (1999) Management of nutrition in European intensive care units: results of a questionnaire. Working Group on Metabolism and Nutrition of the European Society of Intensive Care Medicine. Intensive Care Medicine 25, 95-101.

Raina N \& Jeejeebhoy KN (2004) Effect of low-protein diet and protein supplementation on the expressions of TNF-alpha TNFR-I, and TNFR-II in organs and muscle of LPS-injected rats. American Journal of Physiology 286, E481-E487.

Raina N, Lamarre J, Liew CC, Lofti AH \& Jeejeebhoy KN (1999) Effect of nutrition on tumor necrosis factor receptors in weight-gaining and -losing rats. American Journal of Physiology 277, E464-E473.

Rayman MP (2000) The importance of selenium to human health. Lancet 356, 233-241.

Rennie MJ, Ahmed A, Khogali SE, Low SY, Hundal HS \& Taylor PM (1996) Glutamine metabolism and transport in skeletal muscle and heart and their clinical relevance. Journal of Nutrition 126, Suppl. 4, 1142S-1149S.

Rennie MJ, Hundal HS, Babij P, MacLennan P, Taylor PM, Watt PW, Jepson MM \& Millward DJ (1986) Characteristics of a glutamine carrier in skeletal muscle have important consequences for nitrogen loss in injury, infection, and chronic disease. Lancet ii, 1008-1012.

Ritz MA, Fraser R, Edwards N, Di Matteo AC, Chapman M, Butler R, Cmielewski P, Tournadre JP, Davidson G \& Dent J (2001) Delayed gastric emptying in ventilated critically ill patients: measurement by $13 \mathrm{C}$-octanoic acid breath test. Critical Care Medicine 29, 1744-1749.

Ritz MA, Fraser R, Tam W \& Dent J (2000) Impacts and patterns of disturbed gastrointestinal function in critically ill patients. American Journal of Gastroenterology 95, 30443052.

Roth E, Manhart N \& Wessner B (2004) Assessing the antioxidative status in critically ill patients. Current Opinion in Clinical Nutrition and Metabolic Care 7, 161-168.

Schofield WN (1985) Predicting basal metabolic rate, new standards and review of previous work. Human Nutrition Clinical Nutrition 39, Suppl. 1, 5-41.

Seth A, Basuroy S, Sheth P \& Rao RK (2004) L-Glutamine ameliorates acetaldehyde-induced increase in paracellular permeability in Caco-2 cell monolayer. American Journal of Physiology 287, G510-G517.

Shaw SN, Elwyn DH, Askanazi J, Iles M, Schwarz Y \& Kinney JM (1983) Effects of increasing nitrogen intake on nitrogen balance and energy expenditure in nutritionally depleted adult patients receiving parenteral nutrition. American Journal of Clinical Nutrition 37, 930-940.

Simpson F \& Doig GS (2005) Parenteral vs. enteral nutrition in the critically ill patient: a meta-analysis of trials using the intention to treat principle. Intensive Care Medicine 31, $12-23$.
Soulsby CT, Khela M, Yazaki E, Evans DF, Hennessy E \& Powell-Tuck J (2006) Measurements of gastric emptying during continuous nasogastric infusion of liquid feed: Electric impedance tomography versus gamma scintigraphy. Clinical Nutrition 25, 671-680.

Tjader I, Rooyackers O, Forsberg AM, Vesali RF, Garlick PJ \& Wernerman J (2004) Effects on skeletal muscle of intravenous glutamine supplementation to ICU patients. Intensive Care Medicine 30, 266-275.

Travis SF, Sugerman HJ, Ruberg RL, Dudrick SJ, DelivoriaPapadopoulos M, Miller LD \& Oski FA (1971) Alterations of red-cell glycolytic intermediates and oxygen transport as a consequence of hypophosphatemia in patients receiving intravenous hyperalimentation. New England Journal of Medicine 285, 763-768.

Van den Berghe G (2004) How does blood glucose control with insulin save lives in intensive care? Journal of Clinical Investigation 114, 1187-1195.

Van den Berghe G, Wilmer A, Hermans G, Meersseman W, Wouters PJ, Milants I, Van Wijngaerden E, Bobbaers H \& Bouillon R (2006) Intensive insulin therapy in the medical ICU. New England Journal of Medicine 354, 449-461.

van den Berghe G, Wouters P, Weekers F, Verwaest C, Bruyninckx F, Schetz M, Vlasselaers D, Ferdinande P, Lauwers P \& Bouillon R (2001) Intensive insulin therapy in critically ill patients. New England Journal of Medicine 345, 1359-1367.

Wernerman J \& Hammarqvist F (1999) Modulation of endogenous glutathione availability. Current Opinion in Clinical Nutrition and Metabolic Care 2, 487-492.

Wessner B, Strasser EM, Spittler A \& Roth E (2003) Effect of single and combined supply of glutamine, glycine $\mathrm{N}$ acetylcysteine, and R,S-alpha-lipoic acid on glutathione content of myelomonocytic cells. Clinical Nutrition 22, 515-522.

Wischmeyer PE (2006) Glutamine: the first clinically relevant pharmacological regulator of heat shock protein expression? Current Opinion in Clinical Nutrition and Metabolic Care 9, 201-206.

Wischmeyer PE, Lynch J, Liedel J, Wolfson R, Riehm J, Gottlieb L \& Kahana M (2001) Glutamine administration reduces Gram-negative bacteremia in severely burned patients: a prospective, randomized, double-blind trial versus isonitrogenous control. Critical Care Medicine 29, 2075-2080.

Wolfe RR (2005) Regulation of skeletal muscle protein metabolism in catabolic states. Current Opinion in Clinical Nutrition and Metabolic Care 8, 61-65.

Wolfe RR, Goodenough RD, Burke JF \& Wolfe MH (1983) Response of protein and urea kinetics in burn patients to different levels of protein intake. Annals of Surgery 197, 163-171.

Wolfe RR \& Martini WZ (2000) Changes in intermediary metabolism in severe surgical illness. World Journal of Surgery 24, 639-647.

World Health Organization/Food and Agriculture Organization (2004) Vitamin and Mineral Requirements in Human Nutrition, 2nd ed., p. 209. Geneva: WHO.

Ziegler TR, Ogden LG, Singleton KD, Luo M, FernandezEstivariz C, Griffith DP, Galloway JR \& Wischmeyer PE (2005) Parenteral glutamine increases serum heat shock protein 70 in critically ill patients. Intensive Care Medicine 31, 1079-1086. 